\begin{tabular}{|c|c|c|c|c|}
\hline $\begin{array}{c}\text { Jurnal Penelitian \& } \\
\text { PPM }\end{array}$ & ISSN: 2442-448X & Vol 4, No: 2 & Hal: $129-389$ & Juli 2017 \\
\hline
\end{tabular}

\title{
DILEMA SUPERVISI DALAM PRAKTIK SUPERVISI PEKERJAAN SOSIAL
}

\author{
OLEH: \\ SIDIK SANDI SABANA, FADILLA RAMA WIDAPRATAMA, RUDI SAPRUDIN DARWIS \\ 1. Mahasiswa Program Studi Ilmu Kesejahteraan Sosial FISIP Universitas Padjadjaran \\ 2. Mahasiswa Program Studi IImu Kesejahteraan Sosial FISIP Universitas Padjadjaran \\ 3. Departemen Kesejahteraan Sosial FISIP Universitas Padjadjaran
}

Email:

(sidiksandis@gmail.com; fadillaramawidapratama35@gmail.com; rudi.darwis@unpad.ac.id)

\begin{abstract}
ABSTRAK
Supervisi adalah suatu proses penjaminan di dalam praktik pekerjaan sosial agar pekerja sosial dapat bekerja dengan benar. Tujuan dari adanya supervisi sendiri yaitu untuk menjamin proses pemberian layanan kepada klien dapat berjalan secara efektif dan berkualitas. Dilema supervisi adalah suatu hal yang terjadi ketika terdapat krisis di dalam praktik supervisi pekerjaan sosial. Pada dasarnya krisis supervisi terjadi sebagai hasil dari interaraksi antara supervisor dengan supervisee, baik itu karena adanya disfungsi dari supervisor maupun supervisee. Krisis supervisi jika dibiarkan tentu saja akan berdampak tidak baik bagi hubungan supervisor dengan supervisee sebab di antaran supervisor dan supervisee harus terjadi suatu hubungan yang erat dan saling melengkapi satu sama lain. untuk menghindari terjadinya krisis dalam supervisi harus ada kesadaran di antara supervisor maupun supervisee untuk saling terbuka ketika sedang dalam proses supervisi agar pada nantinya tidak lagi terjadi krisis di antara hubungan supervisor dengan supervisee yang dapat menimbulkan dilema supervisi.
\end{abstract}

Kata kunci : krisis supervisi, supervisor, supervisee, hubungan, pekerjaan sosial

\begin{abstract}
Supervision is a process of guarantees in the practice of social work so that social workers can work properly. The purpose of the supervision itself is to ensure the process of providing services to clients can run effectively and quality. Dilemma of supervision is something that occurs when there is a crisis in the practice of social work supervision. Basically a supervision crisis occurs as a result of interaction between the supervisor and the supervisee, either because of the dysfunction of the supervisor or supervisee. Supervision crisis if left unchecked would have a negative impact on supervisor relationships with supervisee because supervisor and supervisee must have a close and complementary relationship with each other. To avoid a crisis in supervision there must be awareness among supervisor and supervisee to be mutually open while in the process of supervision so that in the future there will be no crisis between supervisor relationships with supervisee that can lead to supervision dilemma.
\end{abstract}

Keywords: supervision crisis, supervisor, supervisee, relationship, social work 


\begin{tabular}{|c|c|c|c|c|}
\hline $\begin{array}{c}\text { Jurnal Penelitian \& } \\
\text { PPM }\end{array}$ & ISSN: 2442-448X & Vol 4, No: 2 & Hal: $129-389$ & Juli 2017 \\
\hline
\end{tabular}

\section{PENDAHULUAN}

Pada profesi pekerjaan sosial terdapat suatu proses supervisi di dalam praktik pekerjaan sosial tersebut. Kata supervisi ini sendiri berasal dari bahasa latin, Super ( lebih ) dan Videre (menonton, atau melihat). Orang yang mengawasi disebut supervisor, sedangkan orang yang diawasi disebut dengan supervisee. Oleh karena itu, seorang supervisor dalam hal ini didefinisikan sebagai pengawas, yaitu yang mengawasi hasil kerja orang lain (supervisee) dengan penuh tanggung jawab sesuai dengan prosedur dan kebijakan yang telah ditetapkan oleh lembaga. Supervisi dikatakan juga sebagai proses penjaminan bagi pekerja sosial baru yang akan melanjutkan dari tingkat perkuliahan ke dunia kerja. Dengan demikian proses supervisi dalam praktik pekerjaan sosial yaitu seorang supervisor memberikan pendampingan kepada pekerja sosial baru yang belum berpengalaman agar bisa beradaptasi dan siap bekerja di dunia pekerjaan sosial.

Secara umum Supervisi pekerjaan sosial mempunyai 3 fungsi, yaitu :

1. Fungsi Administrasi

Supervisi administrasi adalah salah satu aspek dari supervisi yang berhubungan dengan administrasi dalam suatu konteks organisasional. Tujuan dari adanya supervisi administrasi ini yaitu untuk menjamin kualitas pelayanan yag diberikan terhadap klien sesuai dengan kebijakan dan prosedur yang terdapat pada lembaga tersebut. Selain itu supervisi administrasi juga memiliki tujuan untuk menyediakan supervisee agar bekerja dengan konteks pekerjaan yang memungkinkan dia untuk melakukan pekerjaan secara efektif.

\section{Fungsi Edukatif}

Supervisi edukatif adalah salah satu aspek dalam supervisi yang berkaitan dengan pemberian proses pembelajaran dan penguatan dari seorang supervisor kepada supervisee. Tujuan dari supervisi edukatif ini adalah memberkan transfer ilmu yaitu skill, attitude, dan knowledge kepada supervisee. Selain itu di dalam supervisi edukatif ini seorang supervisor pun harus berperan dalam mengajarkan serta memberikan pengembangan keterampilan profesional yang berkelanjutan terhadap supervisee itu sendiri.

\section{Fungsi Dukungan}

Supervisi dukungan atau supportif merupakan salah satu aspek dari supervisi yang berfungsi untuk memberikan dukungan terutama dukungan moral kepada supervisee dimana sang supervisor menyemangati supervisee jika pada suatu keadaan supervisee mengalami masalah yang sangat berat dan dia benar-benar membutuhkan dukungan dan semangat dari orang yang bisa dipercaya untuk membantu supervisee agar merasa lebih baik dan tetap tenang di dalam melakukan pekerjaannya. Supervisor pun bertanggung jawab untuk menghilangkan tekanan yang ada pada diri supervisee serta membuat supervisee selalu berada dalam kondisi yang nyaman sehingga supervisee dapat menjalankan tugasnya dengan efektif dan efisien.

Dalam praktik supervisi pekerjaan sosial tentu saja di dalamnya terdapat suatu hubungan antara supervisor dan supervisee. Hubungan antara supervisor dan supervisi ini selayaknya terjadi secara intens dan harmonis. Namun, pada kenyataannya sering terjadi halhal yang tidak diinginkan terjadi di dalam proses supervisi ini seperti adanya kriris supervisi. Krisis supervisi ini dapat terjadi jika terdapat adanya perilaku disfungsional pada salah satu pihak, baik itu disfungsi supervisor 


\begin{tabular}{|c|c|c|c|c|}
\hline $\begin{array}{c}\text { Jurnal Penelitian \& } \\
\text { PPM }\end{array}$ & ISSN: 2442-448X & Vol 4, No: 2 & Hal: $129-389$ & Juli 2017 \\
\hline
\end{tabular}

atau disfungsi supervisee. Lambat laun hal itu akan menimbulkan suatu dilema di dalam proses supervisi itu sendiri.

Krisis supervisi memang merupakan suatu permasalahan yang dapat dikatakan sangat tidak baik bagi hubungan antara supervisosr dengan supervisee. Hal tersebut sebisa mungkin haruslah dihilangkan dan dihindari di dalam proses supervisi. Untuk mencegah terjadinya krisis supervisi di dalam proses supervisi diperlukan suatu tenggang rasa yang baik di antara supervisor dan supervisee agar dapat tercipta suatu hubungan yang harmonis di dalam proses supervisi tersebut. Sehingga akan mencegah terjadinya krisis supervisi dimana krisis supervisi adalah hal yang tidak diinginkan untuk terjadi di dalam proses supervisi.

\section{PEMBAHASAN}

Dalam praktik supervisi pekerjaan sosial tentu saja di dalamnya akan terdapat suatu hubungan antara supervisor dan juga supervisee. Hubungan antara supervisor dan supervisee pada hakikatnya adalah suatu hubungan yang sangat baik di dalam praktik pekerjaan sosial. Dengan adanya hubungan yang harmonis di antara supervisor dan supervisee maka proses pemberian layanan terhadap klien pun akan berjalan secara baik dan efektif pula.

Seorang supervisor haruslah bekerja sesuai dengan protokoler dan prosedur yang menyangkut kode etik supervisor yang tentunya tanpa menghilangkan atau melupakan nilai etika pekerja sosial itu sendiri. Prinsip etiknya adalah supervisor harus mengutamakan tujuan untuk membantu pekerja sosial sebagai supervisee yang membutuhkan dan memusatkan pada permasalahan sosial yang terdapat pada diri klien pekerja sosial tersebut. Terdapat tiga kualitas keadaan yang mendasari relasi supervision yang baik: keaslian, saling hormat dan berpikir positif, serta saling investasi atau keterbukaan untuk saling belajar.
Telah dipastikan bahwa adanya kode nilai etika tersendiri yang harus dipegang teguh oleh seorang supervisor ketika bekerja dengan supervisee antara lain meliputi:

1. Harkat dan Martabat Seseorang; prinsip etik pertama adalah menghormati harkat dan martabat seorang pekerja sosial yang tersupervisi. Pekerjaan sosial merupakan profesi yang melibatkan diri langsung baik dalam setting individu, keluarga, kelompok maupun masyarakat. Oleh sebab itu, setting keterlibatan langsung ini menuntut dari para supervisor pekerja sosial untuk memiliki modal nilai yang menghargai orang lain dalam melakukan interaksi sosial, terutama bila sedang dalam keadaan berhadapan oleh pekerja sosial yang tersupervisi olehnya. Di sinilah peran yang agak memerlukan emosional, karena supervisor harus mampu membantu pekerja sosial tersebut tanpa harus membuat pekerja sosial tersebut merasa gagal dalam menangani kliennya.

2. Mementingkan Hubungan Kemanusiaan; Mementingkan hubungan kemanusiaan merupakan prinsip etik dari pekerja sosial beserta supervisor yang mengakui dan mengutamakan hubungan kemanusiaan. Hubungan kemanusiaan (human relationship) adalah unsur yang sangat penting di dalam proses perubahan sosial. Maka dari itu, menjunjung tinggi hubunga kemanusiaan dan kemasyarakatan harus dilakukan untuk mendukung perubahan sosial agar berjalan secara positif. Hubunga kemanusiaan adalah bagian dari proses pertolongan. Baik antara pekerja sosial dengan klien, maupun antara supervisor dengan pekerja sosial.

3. Integritas; Intergritas merupakan salah satu prinsip nilai etik, yang pada 


\begin{tabular}{|c|c|c|c|c|}
\hline $\begin{array}{c}\text { Jurnal Penelitian \& } \\
\text { PPM }\end{array}$ & ISSN: 2442-448X & Vol 4, No: 2 & Hal: $129-389$ & Juli 2017 \\
\hline
\end{tabular}

intinya supervisor pekerja sosial harus mempunyai perilaku yang dapat dipercaya. Dalam batas tertentu, profesi pekerja sosial adalah seperti dokter, 'mengobati' dan 'menyembuhkan' individu, keluarga, kelompok atau masyarakat yang sedang "sakit". Tanpa adanya perilaku yang dapat dipercaya, supervisor pekerja sosial tidak dapat menjalankan profesi tersebut dengan baik. Integritas setidaknya ditunjukkan dengan konsistensi supervisor pekerja sosial dengan pekerja sosial dengan misi profesional, nilai, prinsip etika, serta standar etika dalam aktivitas pertolongan kepada pekerja sosial yang dilakukannya. Namun, dalam kenyataanya ada saja supervisee yang bahkan meragukan atas kemampuan yang dimiliki supervisor. Atas kasus tersebut, dilakukannya suatu evaluasi bersama oleh keduanya namun dengan catatan apakah rasa trust terhadap supervisor akan tetap ada? Keraguan mungkin akan tetap ada, namun bagi seorang supervisor sendiri hal tersebuat dapat "membunuhnya" dalam proses supervisi yang dilakukan. Jika suatu integritas diragukan, maka keharmonisan dalam praktik professionalnya pun akan berjalan dengan tidak baik. Hal tersebutlah yang membuat supervisor dilema sehingga menimbulkan kegusaran bila supervisee kurang percaya atas kemampuan yang dimiliki oleh supervisornya.

4. Kompetensi. Prinsip etik dari nilai ini adalah supervisor pekerja sosial harus mempraktikkan keahlian profesionalismenya dalam proses pertolongan dan bimbingan kepada pekerja sosial yang tersupervisi olehnya. Dalam hal ini pengetahuan dan skill seorang supersivor pekerja sosial harus terpaut diatas pengetahuan dan skill pekerja sosial yang tersupervisi olehnya untuk menunjang kompetensi dari praktik pekerja sosial. Kebutuhan atas kemampuan yang melebihi supervisee memang dianggap sebagai suatu keharusan, namun sebagai seorang supervisor harus berakting "sempurna" di hadapan supervisee dapat menjadi beban tersendiri. Sulit rasanya bertingkah menjadi pribadi yang berbeda sesuai aslinya. Namun, hal tersebut guna memunculkan integritas yang tinggi dalam perannya terhadap supervisee. Integritas itu pula yang nantinya akan menggambarkan kompetensi yang lebih sebagai modal dalam bekerja dengan supervisee. Tanpa adanya kompetensi tersebutlah yang membuat supervisor pekerja sosial tidak dapat profesional dan mencapai tujuannya dengan baik bersema supervisee. Sehingga adanya pengetahuan dan keahlian yang memadai juga menjadi modal dasar yang sangat penting dalam profesi menjadi supervisor pekerjaan sosial.

Supervisi pekerjaan sosial ini di dalam praktiknya secara umum memiliki tiga fungsi yang ada, yaitu fungsi administratif, fungsi edukatif, dan fungsi dukungan atau supportif. Di dalam menjalankan ketiga fungsi tersebut tentu saja hal yang pertama kali harus dipastikan adalah terciptanya suatu hubungan yang seimbang di antara supervsor dan juga supervisee, yang dimaksud dengan hubungan yang seimbang disini adalah bahwa meskipun secara hierarki posisi supervisor disini adalah sebagai atasan dan supervisee sebagai bawahan, namun tidak boleh ada rasa superior dari supervisor terhadap supervisee, begitupun sebaliknya jangan ada rasa inferior dari supervisee terhadap supervisornya.

Terciptanya suatu hubungan yang seimbang di antara supervisor dan supervisee tentu saja sangat penting di dalam praktik supervisi pekerjaan sosial. Sebab pada dasarnya baik itu supervisor maupun supervisee disini adalah sama-sama belajar, jadi sudah sepantasnya lah harus tercipta suatu 
hubungan yang harmonis. Dengan demikian akan terwujud proses supervisi yang efektif dan proses transfer attitude, skill, dan knowledge dari supervisor terhadap supervisee akan berlangsung dengan baik dan lancar di dalam pengimplementasiannya.

Hubungan antara supervisor dan supervisee memang sudah selayaknya harus berjalan dengan harmonis dan seimbang. Namun, di dalam realita yang terjadi sering kali hubungan antara supervisor dan supervisee ini tidak sesuai dengan apa yang diharapkan. Sering kali muncul dilema dalam proses supervisi. Hal tersebut terjadi dikarenakan adanya krisis supervisi yang terjadi di antara supervisor dan supervisse.

Krisis supervisi yang terjadi di antara supervisor dan supervisee dapat terjadi diakibatkan oleh terjadinya perilaku disfungsional baik itu dari supervisor maupun supervisee itu sendiri. selain itu krisis supervisi yang terjadi sering kali juga terjadi karena dibesar-besarkan, sehingga pada akhirnya muncul krisis supervisi yang dibesar-besarkan oleh supervisor maupun krisis yang dibesarbesarkan oleh supervisee.

Krisis yang dibesar-besarkan oleh supervisor dapat diakibatkan oleh :

1) Adanya isu-isu yang cukup serius di dalam mempelajari sikap-sikap dari supervisee. Misalnya supervisor menganggap bahwa perilaku supervisee dapat menyebabkan terjadinya hambatan di dalam proses penyelesaian masalah.

2) Adanya kegagalan dari supervisee untuk memelihara hubungan yang diperlukan di dalam melakukan proses supervisi yang efektif.

3) Hal-hal yang berhubungan dengan cara kerja supervisee,. Misalnya saja seperti intervensi yang dilakukan oleh supervisee terhadap klien yang dianggap tidak sesuai oleh supervisor.
4) Berbagai hal lain yang dilakukan oleh supervisee yang dianggap menyulitkan oleh supervisor. Misalnya supervisee jarang untuk menemui atau melakukan bimbingan dengan supervisornya dan supervisee tidak tepat waktu di dalam melakukan proses bimbingan dengan supervisor di dalam proses supervisi.

Sementara itu, krisis yang dibesar-besarkan oleh supervisee dapat disebabkan oleh :

1) Hal-hal yang berkaitan dengan kemampuan dari supervisor. Misalnya saja ketika sedang melakukan proses supervisi, sang supervisor tidak menunjukkan sikap dan kemampuan yang seharusnya dimiliki oleh seorang supervisor di dalam praktik supervisi pekerjaan sosial.

2) Hal-hal yang berkaitan dengan isu-isu yang berhubungan dengan teaching method yang dilakukan oleh supervisor. Misalnya saja dari segi attitude, sang supervisor menghina atau mengatakan hal-hal yang tidak pantas terhadap supervisee sehingga menyebabkan si supervisee merasa sakit hati.

3) Hal-hal yang berkaitan dengan perilaku, intervensi, dan cara kerja supervisor terhadap supervisee yang pada akhirnya membuat supervisee mempertanyakan kaulifikasi dari supervisor tersebut.

4) Hal-hal lain yang berkaitan dengan kesulitan-kesulitan yang ditimbulkan oleh supervisor yang muncul di dalam proses supervisi. Misalnya saja supervisor susah sekali untuk ditemui dan juga supervisor sering tidak tepat waktu di dalam melakukan proses supervisi ini.

Krisis supervisi yang dibesar-besarkan menjadi faktor penting yang dapat menjadikan 
hubungan di antar supervisor dan supervisee tidak berjalan dengan seharusnya. Seperti yang diketahui bahwa seharusnya hubungan yang terjadi antar supervisor dan supervisi ini harus berlangsung secara harmonis. Namun dikarenakan adanya krisis supervisi yang terjadi pada akhirnya akan dapat menimbulkan stres dan juga ketegangan di antara hubungan supervisor dan supervisee ini.

Hubungan antara supervisor dan supervisee adalah sumber utama yang memuat ketegangan dan dukungan (Anderson, Schlossberg, dan Rigazio-DiGilio 2000; Hagler dan Casey 1990; Watkins 1997). Mayer dan Rosenblatt, yang memperoleh sekitar 233 protokol situasi stres yang dihadapi oleh praktisi kerja sosial, menyatakan bahwa "kecemasan pekerja pada dasarnya merupakan fungsi dari dua hubungan utama di mana dia terlibat, hubungannya dengan atasannya dan hubungan kliennya" (Mayer dan Rosenblatt 1973b: 3) $)^{9}$.

Berdasarkan referensi di atas dapat dikatakan bahwa di dalam proses supervisi pekerjaan sosial, hubungan antara supervisor dan supervisee dapat menghasilkan dua hal, yaitu ketegangan dan juga dukungan. Selain itu hal yang berpotensi menimbulkan stres bagi supervisee adalah bisa disebabkan oleh hubungannya dengan atasan (supervisor) dan juga hubungannya dengan klien yang sedang ditangani. Oleh karena itu itu baik supervisor maupun supervisee dalam hal ini harus bisa menjaga hubungannya dengan baik sehingga di dalam hubungan mereka tidak akan menghasikan ketegangan tetapi hanya menghasilkan dukungan. Untuk mencapai hal tersebut seorang supervisor harus memahami dan memastikan bahwa fungsi dari supervisi baik itu administratif, edukasi, dan supportif sudah terlaksana dengan baik.

Mengoptimalkan terlaksananya fungsifungsi yang ada di dalam supervisi bisa

\footnotetext{
${ }^{9}$ Alfred Kadushin dan Daniel Harkness. 2002. Supervision In Social Work (Fourth Edition). New York \& Chichester: Columbia University Press. Hal : 229
}

menjadi salah satu cara untuk mengatasi terjadinya dilema supervisi. Fungsi yang paling harus dioptimalkan di sini adalah fungsi supportif atau dukungan. Sebab pada dasarnya situasi yang dapat menyebabkan terjadinya ketegangan dan stres pada supervisee tidak hanya menyangkut dengan hubungan antara supervisee dangan supervisor melainkan juga bisa saja terjadi dikarenakan permasalahan yang sedang terjadi di antara hubungan supervisee dengan klien yang sedang ditanganinya. Dengan demikian supervisor harus mampu untuk terlibat di dalam pemberian dukungan terhadap masalah yang sedang dialami oleh supervisee.

Seorang supervisor disini harus bisa dan mampu untuk memberikan dukungan yang baik terhadap supervisee yang sedang mengalami masalah dengan klien. Karena pada saat seperti ini yang dibutuhkan oleh supervisee adalah dukungan dari orang yang mempercayainya. Di sinilah supervisor dapat memaksimalkan fungsi supervisi supportif untuk mendukung supervisee di dalam menghadapi permasalahannya tersebut sehingga supervisee dapat merasa nyaman. Dengan demikian hal tersebut dapat mencegah terjadinya krisis supervisi di dalam hubungan antara supervisor dan supervisee. Selain itu bagi supervisor sendiri hal tersebut tentu memberikan suatu kebanggaan tersendiri ketika mereka berhasil membangun suatu hubungan yang harmonis dengan supervisee.

Karena ketika supervisee melibatkan supervisor di dalam pengalaman dan permasalahan mereka, supervisor mendapati dirinya juga sedang belajar. Pikiran yang telah stagnan selama bertahun-tahun menjadi terstimulasi dan bergairah. Pengetahuan supervisor tentang dirinya dan manusia lain diperluas, karena supervisor melihat dirinya dan supervisee dalam peran baru yang sebelumnya tidak teramati. ${ }^{10}$

\footnotetext{
${ }^{10}$ Bessie Kent. 1969. Social Work Supervision in Practice. Oxford, London, Edinburgh, New York, Toronto, Sydney, Paris, Braunschweig : Pergamon Press. Hal : 158
} 
Dengan demikian dengan memberikan dukungan kepada supervisee di dalam penyelesaian kasusnya dengan klien yang sedang ditanganinya secara tidak langsung juga akan membuat supervisor menjadi belajar dan menstimulus pemikiran dan pengetahuan mereka kembali. Sehingga hal tersebut secara perlahan akan menambah kualitas dari supervisor itu sendiri, di samping juga dapat mencegah terjadinya krisis supervisi.

Selain itu hal lain yang dapat dilakukan untuk mengatasi terjadinya dilema supervisi dengan menggunakan conscious system (sistem sadar). Conscious system ini dapat digunakan untuk menghadapi situasi krisis supervisi yang terjadi di antara hubungan supervisor dan supervisee. Dalam conscious system ini baik supervisor dan supervisee harus saling memiliki kesadaran bahwa di dalam proses supervisi tidak boleh terjadi krisis. Sebab krisis supervisi dapat mengakibatkan terjadinya hubungan yang tidak baik di antara supervisor dan supervisee.

Supervisor dan supervisee masing-masing harus memiliki gambaran mengenai bagaimana proses berpikir (emosi). Antara supervisor dan supervisee harus bersikap terbuka ketika dalam situasi krisis yang terjadi di saat proses supervisi. Kedua belah pihak harus siap menerima apapun risiko yang terjadi dan timbul dalam situasi krisis tersebut. Hal tersebut dapat berefek kepada tercegahnya krisis supervisi, sehingga pada akhirnya hubungan antara supervisor dan supervisee dapat berjalan dengan harmonis dan efektif. Dengan demikian maka tidak akan terjadi dilema supervisi di dalam proses supervisi pekerjaan sosial.

\section{PENUTUP}

\section{Kesimpulan}

Supervisi pekerjaan sosial adalah suatu proses penjaminan agar pekerja sosial dapat bekerja dengan benar. Di dalam supervisi pekerjaan sosial ini terdapat tiga fungsi yaitu administratif, edukatif, dan supportif. Dalam praktik supervisi pekerjaan sosial tentu saja di dalamnya akan terdapat suatu hubungan antara supervisor dan juga supervisee. Hubungan antara supervisor dan supervisee pada hakikatnya adalah suatu hubungan yang harus berjalan secara harmonis di dalam praktik pekerjaan sosial. Namun, di dalam realita yang terjadi sering kali hubungan antara supervisor dan supervisee ini tidak sesuai dengan apa yang diharapkan. Sering kali muncul dilema dalam proses supervisi. Hal tersebut terjadi dikarenakan adanya krisis supervisi yang terjadi di antara supervisor dan supervisse. Krisis supervisi ini dapat terjadi jika terdapat adanya perilaku disfungsional pada salah satu pihak, baik itu disfungsi supervisor atau disfungsi supervisee.

Krisis supervisi yang terjadi di dalam hubungan antara supervisor dan supervisee dapat pula terjadi karena dibesar-besarkan baik itu oleh supervisor maupun supervisee. Krisis yang dibesar-besarkan oleh supervisor lebih banyak kepada proses penanganan supervisee terhadap klien. Sementara krisis supervisi yang dibesar-besarkan oleh supervisee lebih banyak kepada sikap supervisor yang tidak peka atau tidak sungguh-sungguh di dalam menangani permasalahan dari supervisee. Untuk mencegah terjadinya krisis supervisi di dalam praktik pekerjaan sosial ini dapat melalui dua hal yaitu dengan mengoptimalkan fungsi supervisi, khususnya fungsi supportif dan juga dengan menggunakan conscious system. Dengan demikian maka dapat mencegah terjadinya dilema supervisi di dalam proses supervisi pekerjaan sosial.

\section{Saran}

Dilema supervisi adalah sesuatu yang sangat tidak baik jika terjadi di dalam proses supervisi pekerjaan sosial. Oleh karena itu, saran yang dapat penulis sampaikan di sini adalah sebaiknya bagi seorang supervisor harus dapat memahami dan mendukung supervisee agar supervisee tersebut dapat merasa nyaman. Begitu juga bagi supervisee, mereka harus dapat berperilaku baik dan 


\begin{tabular}{|c|c|c|c|c|}
\hline $\begin{array}{c}\text { Jurnal Penelitian \& } \\
\text { PPM }\end{array}$ & ISSN: 2442-448X & Vol 4, No: 2 & Hal: $129-389$ & Juli 2017 \\
\hline
\end{tabular}

menunjukkan sikap hormat terhadap supervisor. Jika hal tersebut dapat terlaksana, maka dapat dipastikan akan tercipta suatu hubungan yang baik di antara supervisor dan supervisee di dalam praktik supervisi pekerjaan sosial.

Mengenai saran dari penulis pribadi di dalam menyusun atikel ini, penulis mengalami sedikit kendala yaitu mengenai masih minimnya kajian literatur tentang supervisi yang akan dijadikan sebagai referensi di dalam penulisan artikel ini. Adapun saran yang ingin disampaikan dari dalam diri penulis pribadi diantaranya adalah agar ke depannya dapat diperbanyak literatur mengenai supervisi pekerja sosial ini sendiri terutama literatur yang berbahasa Indonesia. Sebab hal itu akan sangat membantu sekali bagi para mahasiswa khususnya bagi mahasiswa yang ingin menjadi seorang calon pekerja sosial serta mempunyai ketertarikan dalam aspek supervisi pekerjaan sosial.

\section{DAFTAR PUSTAKA}

Huda, Miftachul. 2009. Pekerjaan Sosial dan Kesejahteraan Sosial: Sebuah Pengantar. Cetakan Pertama. Yogyakarta: Pustaka Pelajar

Kadushin, Alfred dan Daniel Harkness. 2002. Supervision In Social Work (Fourth Edition). New York \& Chichester: Columbia University Press.

Kent, Bessie. 1969. Social Work Supervision in Practice. Oxford, London, Edinburgh, New York, Toronto, Sydney, Paris, Braunschweig : Pergamon Press.

Raharjo, ST. 2015. Assessment untuk Praktik Pekerjaan Sosial dan Kesejahteraan Sosial. Bandung: Unpad Press 2015. Dasar Pengetahuan Pekerjaan Sosial. Bandung: Unpad Press. 2015. Keterampilan Pekerjaan Sosial: Dasar-dasar. Bandung, Unpad Press. 